\title{
INFLUÊNCIA DA VARIÁVEL AMBIENTAL NO PROCESSO DE ESCOLHA DOS FORNECEDORES: UM ESTUDO EM AGROINDÚSTRIAS DA MICRORREGIÃO DE ASSIS-SP
}

\author{
E.C.Oliveira ${ }^{{ }^{*}}$ \\ 1 Universidade Federal de São Carlos - UFSCar, 13565-905, São Carlos - SP, Brasil \\ * edeniscesar@ufscar.br
}

Artigo submetido em 28/01/2016 e aceito em 20/08/2016

\section{RESUMO}

O mercado global, caracterizado pela competitividade, tem exigido das organizações novos posicionamentos, sobretudo quanto à forma como implementam e desenvolvem relações com seus parceiros comerciais. A Gestão da Cadeia de Suprimentos desponta como uma ferramenta que proporciona às organizações o gerenciamento mais efetivo dos desdobramentos dessas relações. A incorporação das questões ambientais no âmbito organizacional repercutiu diretamente em toda cadeia. As organizações passaram a considerar a sustentabilidade como fator preponderante nas relações com seus stakeholders, justificando o surgimento da Gestão Sustentável da Cadeia de Suprimentos. O estudo objetiva analisar a influência da variável ambiental introduzida nas decisões e seleção dos fornecedores das
\end{abstract}

agroindústrias de cana-de-açúcar localizadas na Microrregião de Assis-SP. Realizou-se Estudo de Múltiplos Casos em seis agroindústrias, coletando dados através de entrevista semiestruturada, aplicada a dezesseis atores diretamente envolvidos com o assunto abordado, além da análise documental como suporte às entrevistas. Para análise dos dados, aplicou-se a análise de conteúdo com auxílio do software ATLAS.ti. Os resultados evidenciaram que, das seis empresas pesquisadas, nas agroindústrias AGR2, FOR1 e FOR2 a variável ambiental apresenta fraca influência na seleção de seus fornecedores; na AGR1 a influência é mediana e, somente nas agroindústrias AGR3 e AGR4 a variável ambiental exerce forte influência.

\section{ENVIRONMENTAL VARIABLE INFLUENCE IN THE PROCESS OF SUPPLIERS CHOICE: A STUDY IN AGRIBUSINESS IN THE MICROREGION OF ASSIS-SP}

\begin{abstract}
The global market characterized by competition, has demanded of new placements organizations, particularly as to how implement and develop relations with its trading partners. The Supply Chain Management emerges as a tool that provides organizations with the most effective management of the consequences of these relations. The incorporation of environmental issues in the organizational context reflected directly across chain. Organizations began to consider sustainability as a major factor in relations with its stakeholders, justifying the emergence of Sustainable Management of Supply Chain. The study aims to analyze the influence of environmental variable introduced in decisions and selection of
\end{abstract}

suppliers of sugarcane agro-industries located in the micro-region of Assis-SP. Was held from Multiple Case Study in six agribusinesses, collecting data through semistructured interviews, applied to sixteen actors directly involved with the subject matter, in addition to document analysis to support the interviews. For data analysis, applied to content analysis with the help of ATLAS.ti software. The results showed that, of the six surveyed companies, in agribusiness AGR2, FOR1 and for2 the environmental variable has a weak influence in the selection of its suppliers; in AGR1 the influence is average and only in AGR3 and AGR4 agribusinesses environmental variable has a strong influence.

KEYWORDS: Environmental Management, Sustainable Management of Supply Chain, Sugarcane Industry, Suppliers, Environment. 


\section{INTRODUÇÃO}

Por muito tempo, a sociedade, de modo geral, somente considerou os benefícios econômicos advindos das atividades empresariais. Benefícios como produtos e serviços que atendiam as suas necessidades, desde as mais básicas até as mais sofisticadas, o emprego de mão-de-obra como fator gerador de renda para o trabalhador assalariado, a maximização do capital, entre outros.

A rigor, os ganhos sociais eram bastante vultosos a ponto de impedir o questionamento sobre o alto preço pago pela sociedade ao absorver os custos externos do sistema, sobretudo quanto aos impactos ambientais com consequências nefastas ao ecossistema como um todo. De fato, não se imputava tal responsabilidade às empresas, uma vez que seu dever precípuo era garantir o crescimento econômico e, em tempos mais acirrados, a estabilidade econômica. Dessa forma, os custos externos não eram sequer reconhecidos como custos, não eram, portanto, contabilizados. Nesse sentido assere Bauen (2005, p. 163):

Os custos e benefícios totais das atividades econômicas frequentemente não são calculados. Os processos de tomada de decisão consideram os custos e benefícios privados, mas, na maioria das vezes, ignoram uma série de custos e benefícios adicionais, conhecidos como externalidades, com os quais a sociedade arca.

Um exemplo emblemático de externalidade constitui-se nos próprios danos causados pela poluição. A contabilização dos custos totais das atividades econômicas é um possível passo na busca de estratégias para se chegar a um desenvolvimento sustentável (BAUEN, 2005). O conceito de externalidade é constituinte da teoria econômica neoclássica do bem-estar, elaborado pela primeira vez por Arthur Pigou. As externalidades são resultado de falhas no mercado, que contribuem para que determinados efeitos das atividades econômicas não sejam considerados no processo de transação (PIGOU, 1932).

Bauen (2005) considera importante que esses efeitos sejam considerados, uma vez que representam os efeitos das atividades econômicas sobre a sociedade de forma totalitária e não somente sobre as partes envolvidas na transação econômica. Consequentemente, pode melhor refletir preferências sociais em oposição a preferências individuais.

A partir da década de 1970, esse cenário começa a sofrer mudanças crescentes, impactando diretamente o ambiente em que as empresas operam. Assim, as organizações que eram vistas unicamente como instituições econômicas com responsabilidades delimitadas a esse contexto, presenciam o surgimento de exigências de novas variáveis do ambiente externo, o que passa a exigir novos arranjos institucionais, novos modelos de gestão, como resposta à pressão ambiental.

Pressões ambientais podem ser compreendidas como contingências que afluem no ambiente institucional, exercendo pressão sobre as organizações para que se ajustem a práticas, comportamentos e configurações isomórficas. Além disso, por intermédio de seus componentes normativos, regulatórios, culturais e cognitivos, as instituições, assim que recebem a influência dessas pressões, engendram concepções visando prover a estabilidade e acepção para a vida social (DIMAGGIO e POWELL, 1991; SCOTT, 2014).

Não obstante a isso, a inserção da variável ambiental no modus operandi corporativo tem se tornado questão obrigatória em função da maior influência dos seus stakeholders, impulsionada, sobretudo pelo maior acesso à informação somando-se à crescente exigência de transparência por parte das empresas (compliance). De alguma forma as empresas procuram se adequar, especialmente no cumprimento dos aspectos legais do negócio e sua relação com o meio ambiente, considerando os impactos causados por suas atividades, desde a extração da matéria-prima, passando pelo processo de transformação, culminando na eliminação dos rejeitos e efluentes 
oriundos desse "metabolismo". Nesse cenário estão compreendidas as agroindústrias canavieiras, produtoras de açúcar, etanol e, mais recentemente, de bioenergia, produzida a partir da queima da biomassa. As atividades dessas agroindústrias são altamente impactantes, considerando desde o manejo do solo para o plantio até o escoamento dos resíduos e efluentes oriundos do processo produtivo.

O setor sucroalcooleiro apresentou significativa evolução na última década, a ponto de passar a ser denominado de setor sucroenergético (OLIVEIRA et al., 2013), mormente ao passar a inserir, prioritariamente, a produção de energia, o que o coloca na vanguarda de um momento histórico de transição da matriz energética. As fontes de energia renováveis são variadas e objeto de investimentos e interesse em todo o mundo (SALLES-FILHO, 2015). O setor é fortemente regulamentado, especialmente no que se refere às restrições ambientais. Órgãos governamentais, poder público, a sociedade civil organizada, e, mais recentemente, como exigência para exportação de seus produtos, a comunidade internacional, têm exercido forte pressão sobre essas empresas.

$\mathrm{Na}$ complexidade desse circuito, a agroindústria, como as demais empresas de outros setores, não está isolada em seu negócio. Há uma cadeia extremamente ativa e necessária à operacionalização de todo processo industrial. Nesse contexto, os fornecedores exercem um papel estratégico, sendo considerados importantes players que compõem esse conjunto de relações complexas, cujo resultado final positivo depende, majoritariamente, de uma gestão organizacional eficiente.

No âmago dessa ambiência, apresenta-se com elevado nível de relevância a gestão ambiental empresarial, que pode ser definida como "um conjunto de políticas e procedimentos internos elaborados a partir da inserção da variável ecológica no âmbito da organização, influenciando desde a formulação de sua estratégia corporativa e seus desdobramentos, passando pela disponibilização do produto/serviço final no mercado e, quando for o caso, a responsabilização pelo recolhimento e correta destinação das embalagens e materiais descartados, sempre visando o seu melhor desempenho ambiental" (OLIVEIRA, 2015).

De forma mais ampla, Gavira (2015) postula que gerenciar a sustentabilidade exige, necessariamente, planejamento, criação, implantação e gestão de estratégias organizacionais que levem em conta o uso eficiente e eficaz dos recursos ambientais, econômicos e sociais por diversos grupos de interesse (stakeholders), no prazo de muitas gerações. A rigor, a partir de uma perspectiva da teoria das organizações, empresas associam-se a outras com o objetivo de aumentar sua eficiência operacional, potencializar seus resultados (eficácia operacional), além de reforçar as relações interorganizacionais e interpessoais (PARMIGIANI e RIVERA-SANTOS, 2011). Diante do exposto, a questão de pesquisa norteadora desse estudo pode ser descrita da seguinte maneira: $A s$ agroindústrias localizadas na Microrregião de Assis-SP consideram a variável ambiental nas decisões sobre seleção/contratação dos seus fornecedores?

Para responder tal questionamento, essa pesquisa objetiva analisar a influência da variável ambiental introduzida nas decisões e seleção dos fornecedores das agroindústrias de cana-de-açúcar localizadas na Microrregião de Assis-SP.

\section{REFERENCIAL TEÓRICO}

\subsection{Gestão Ambiental Empresarial}

A responsividade requerida das empresas em função das forças/pressões advindas do ambiente externo e, mais especificamente as questões ambientais refletidas no tripé da sustentabilidade (econômico - social - ambiental), impacta no ambiente corporativo das 
organizações, que passam a buscar um redimensionamento de sua estrutura organizacional a fim de estimular a criação de novos arranjos organizacionais que contemplem, obrigatoriamente, a revisão de suas práticas com o fito de evitar a degradação do meio ambiente.

Disso, decorre a necessidade de conceber a gestão ambiental empresarial como uma estrutura específica (setor/departamento) dentro da estrutura geral, com finalidades e competências exclusivas, sem, contudo, abrir mão de operar sobre o princípio da cooperação, de forma intersetorial/interdepartamental e, quando possível, ser constituída de equipe multifuncional. O desafio, portanto, está lançado. Segundo Christie et al. (1995), gestão ambiental consiste num conjunto de técnicas e disciplinas que orientam as empresas na adoção de uma produção mais limpa, sobretudo por meio de ações que visam a prevenção de perdas e poluição.

De forma mais abrangente, gestão ambiental refere-se à organização de todo processo de inovação para fomentar a sustentabilidade, com repercussão direta na redução de resíduos, aprimoramento da responsabilidade social, busca da vantagem competitiva (RONDA-PUPO e GUERRAS-MARTIN, 2012) via aprendizado e desenvolvimento contínuo, além do estabelecimento de metas e estratégias ambientais totalmente integradas com os objetivos e estratégias organizacionais (HADEN et al., 2009).

A gestão ambiental deve abarcar todas as atividades da empresa com o fito de minimizar os efeitos de suas atividades sobre o meio ambiente, da mesma forma que deve gerenciar ou responder aos efeitos do ambiente sobre a empresa (SHARFMAN et al., 1997). Carvalho (2011) destaca que a influência dos stakeholders pode ser fator determinante na adoção de práticas sustentáveis pelas empresas. Servem como molas propulsoras ao estabelecerem metas mais elevadas no compromisso empresarial com o meio ambiente. Na concepção de Meixell e Luoma (2015), os stakeholders têm papel chave na construção de uma cadeia de suprimentos com foco na sustentabilidade.

Contudo, a empresa não atua isoladamente no mercado; pelo contrário, as relações corporativas são cada vez mais complexas, o que Parmigiani e Rivera-Santos (2011) definem como relacionamentos interorganizacionais. Assim, da empresa focal passa-se a demandar uma gestão eficiente na relação com seus parceiros comerciais, especialmente seus fornecedores. Nesse sentido, com o intuito de impedir que a empresa focal se submeta a riscos de reputação (branding) ou, ainda, em desgaste de sua imagem pós dano, enceta-se e consolida-se um processo de agrupamento de critérios sociais e ambientais na avaliação para seleção de fornecedores (SEURING e MÜLLER, 2008).

\subsection{Gestão Sustentável da Cadeia de Suprimentos}

Em geral, todas as organizações possuem condições de incorporar práticas de priorizem a sustentabilidade ao longo de sua cadeia de suprimentos (BESKE e SEURING, 2014), sobretudo ao priorizarem ações proativas - que estejam para além daquelas exigidas por lei ou normas regulamentadoras (GONZÁLEZ-BENITO, 2008) -, nas práticas de gestão destinadas à melhoria do seu desempenho. Reconhece-se que essa perspectiva é possível, porém, por enquanto não é o foco da maioria das organizações (SILVA et al., 2015).

A assertiva de Silva et al. (2015) já havia sido apontada por Seuring et al. (2008) ao afirmarem que as organizações têm adotado, tradicionalmente, posturas reativas quando submetidas às pressões de grupos externos, o que pode ser corroborado por outros estudos que apontam ações ambientais empresariais reativas (AZZONE e BERTELÉ; VASTAG et al., 1996; JABBOUR, 2010). Não obstante os ganhos ambientais, com a implementação de práticas socioambientais na cadeia de suprimentos, a empresa pode obter ganhos em termos econômicos, além de vantagens 
competitivas se comparada a outras empresas que não preenchem os requisitos de sustentabilidade (CARTER e ROGERS, 2008).

A terminologia Supply Chain Management - SCM foi utilizada no decorrer dos anos 1980 para descrever os fluxos de materiais entre as organizações. No início da década de 1990, o termo passou a representar três principais aspectos: i) um sinônimo de logística; ii) um suplemento ao conceito de logística; e, iii) um conjunto de atividades e processos relacionados à integração de negócios que notoriamente direcionavam algo que extrapolava o conceito convencional (COOPER et al., 1997).

Destarte, o campo de estudo da SCM seja relativamente novo (GONZÁLEZ-LOUREIRO et al., 2015), o número de pesquisas na área tem crescido exponencialmente, o que justifica o surgimento de vários periódicos nacionais e internacionais (journals) com foco exclusivo em publicações que versam sobre a temática gestão da cadeia de suprimentos. A Tabela 1 apresenta os principais periódicos internacionais que publicam artigos sobre SCM.

Tabela 1 - Principais journals com publicações exclusivas sobre SCM

\begin{tabular}{|c|c|c|}
\hline Journal & $\begin{array}{r}\mathrm{N}^{\circ} \text { de } \\
\text { Artigos }\end{array}$ & $\%$ \\
\hline Supply Chain Management: An International Journal & 517 & م25 \\
\hline International Journal of Physical Distribution \& Logistics Management & $31 /$ & $\begin{array}{l}15,20 \\
1103\end{array}$ \\
\hline International Journal of Production Economics & 406 & 11,93 \\
\hline The International Journal of Logistics Management & 352 & 10,35 \\
\hline International Journal of Production Research 2186.41 & 238 & 7,00 \\
\hline International Journal of Operations \& Production Management & 218 & 6,41 \\
\hline Journal of Operations Management & 210 & 6,17 \\
\hline $\begin{array}{l}\text { Journal of Uperations nanagement } \\
\text { Journal of Business Logistics }\end{array}$ & 195 & 5,73 \\
\hline $\begin{array}{l}\text { Journal of Business Logistics } \\
\text { Journal of Supply Chain Management }\end{array}$ & 167 & 4,91 \\
\hline European Journal of Operational Res & 159 & 4,67 \\
\hline $\begin{array}{l}\text { European Journal of Operational Research } \\
\text { Transportation Research Part E: Logistics and Transportation Review }\end{array}$ & 139 & 4,09 \\
\hline $\begin{array}{l}\text { Production Planning and Control } \\
\text { Plow }\end{array}$ & 116 & 3,41 \\
\hline International Journal of Logistics Sys & 94 & 2,76 \\
\hline $\begin{array}{l}\text { International Journal of Logistics Sys } \\
\text { Production and Operations Managem }\end{array}$ & 68 & 2,00 \\
\hline Journal of Cleaner Production & 65 & 1,91 \\
\hline Journal of Purchasing and Supply Management & 60 & 1,76 \\
\hline $\begin{array}{l}\text { Journal of Purchasing and Supply Management } \\
\text { Transportation Journal }\end{array}$ & 59 & 1,73 \\
\hline European Journal of Purchasing and S & 57 & 1,65 \\
\hline International Journal of Services and Operations M & 47 & 1,38 \\
\hline $\begin{array}{l}\text { International Journal of Services and Operations } \mathrm{M} \\
\text { Journal of the Operational Research Society }\end{array}$ & 40 & 1,18 \\
\hline $\begin{array}{l}\text { Journal of the Operational Research } S \\
\text { International Journal of Logistics Rest }\end{array}$ & 35 & 1,03 \\
\hline $\begin{array}{l}\text { International Journal of Logistics Rese } \\
\text { Manufacturing and Service Operation }\end{array}$ & 31 & 0,91 \\
\hline $\begin{array}{l}\text { Manufacturing and Service Operations } \\
\text { International Journal of Informati }\end{array}$ & 29 & 0,85 \\
\hline $\begin{array}{l}\text { International Journal of Informatior } \\
\text { Management }\end{array}$ & 24 & 0,71 \\
\hline $\begin{array}{l}\text { Management } \\
\text { Operations Research }\end{array}$ & 16 & 0,47 \\
\hline $\begin{array}{l}\text { Operations Research } \\
\text { International Journal }\end{array}$ & 15 & 0,44 \\
\hline International Journal of Integrated Supply Management & 11 & 0,32 \\
\hline Logistics Research & 8 & 0,24 \\
\hline Asia-Pacific Journal of Operational Res & 6 & 0,18 \\
\hline Operations Management Research & 6 & 0,18 \\
\hline International Journal of Shipping and & 6 & 0,18 \\
\hline International Journal of Operations a & 4 & 0,12 \\
\hline Asian Journ & 3 & 0,09 \\
\hline Operational Research & 1 & 0,03 \\
\hline International Review of Retail, Distribution and Consumer Research & 1 & 0,03 \\
\hline TOTAL & 3,402 & 100,00 \\
\hline
\end{tabular}

Fonte: GONZÁLEZ-LOUREIRO et al. (2015, p. 162). 
No âmbito nacional dois periódicos são destaque: Revista Produção, sob responsabilidade do Departamento de Engenharia de Produção da Escola Politécnica da Universidade de São Paulo (PRO/EPUSP); Revista Gestão \& Produção, uma publicação do Departamento de Engenharia de Produção da Universidade Federal de São Carlos - UFSCAR, ambas com periodicidade quadrimestral e conceito Qualis/CAPES A2.

A literatura sobre a temática tende a crescer à medida em que os players e os pesquisadores constatam que a gestão ambiental não termina nos limites corporativos (ZHU et al., 2005). Segundo Lambert et al. (1998, p. 1) gestão da cadeia de suprimentos consiste na "integração de processoschave de negócio, desde os usuários finais aos fornecedores originais que provêem mercadorias, serviços e informação, que adiciona valor aos clientes e outros stakeholders."

$\mathrm{Na}$ convergência da área de pesquisa em gestão ambiental e SCM encontra-se a gênese das abordagens que dispensam exclusivo tratamento de temas ambientais em relações interorganizacionais (SRIVASTAVA, 2007; CARVALHO, 2011).

Assim, no entendimento de Carvalho (2011), as raízes em gestão ambiental empresarial fundamentam o uso da terminologia gestão ambiental da cadeia de suprimentos (Supply Chain Environmental Management - SCEM), cujo conceito compreende "[...] uma ampla faixa de atividades como seleção de fornecedores por desempenho ambiental, ação colaborativa em iniciativas de design verde e provisão de treinamento ou apoio para construir capacidade de gestão ambiental junto a fornecedores" (LIPPMAN, 2001, p. 11).

Segundo Zsidisin e Siferd (2001), gestão ambiental da cadeia de suprimentos pode ser definida como um conjunto de políticas de gerenciamento dessa cadeia, ações e medidas tomadas, bem como as relações formadas como resposta às preocupações com o ambiente natural relativo à concepção, aquisição, produção, distribuição, utilização, reutilização e disposição de produtos e serviços da empresa. Deve-se contemplar todos os possíveis efeitos ambientais nos processos das cadeias de suprimentos, desde a extração das matérias primas até a disposição final dos produtos (EMMETT e SOOD, 2010).

Zhu e Sarkis (2004) reiteram que a Green Supply Chain Management - GSCM (termo que se consolidou no campo de pesquisa [CARVALHO, 2011]) parte desde as ações mais reativas até as práticas mais proativas de gestão ambiental, incluindo a reciclagem, recuperação e a logística reversa.

GSCM pode, também, ser conceituada como a incorporação das questões ambientais à SCM, integrando o design do produto, a busca e seleção de materiais, processos de produção, disponibilização do produto final ao consumidor, além da gerenciamento do término do ciclo do produto vencido seu prazo de vida útil, objetivando reduzir o impacto ecológico das atividades empresariais sem renunciar aspectos como qualidade, custo, confiabilidade e desempenho, ultrapassando os limites do atendimento à legislação ambiental, por meio de práticas que mitiguem os danos ambientais e dimanem lucratividade para a empresa (SRIVASTAVA, 2007).

Sarkis et al. (2011) referindo-se ao conceito de GSCM e os seus diversos elementos, aponta os mais variados desdobramentos na sua definição e terminologia ocorridos ao longo dos anos, listando alguns dos termos que caracterizam esse conceito:

- Gerenciamento da rede de abastecimento sustentável (CRUZ e MATSYPURA, 2009; YOUNG e KIELKIEWICZ-YOUNG, 2001);

- Incorporação da responsabilidade socioambiental à rede de abastecimento (CRUZ e MATSYPURA, 2009; KOVÁCS, 2004);

- Gestão ambiental da cadeia de suprimentos (SHARFMAN et al., 2009); 
- Compras ecológicas (MAIN e GALLE, 1997) e contratos (GÜNTHER e SCHEIBE, 2006);

- Compra ambiental (CARTER et al., 2000; ZSIDISIN e SIFERD, 2001);

- Logística verde (MURPHY e POIST, 2000) e logística ambiental (GONZÁLEZ-BENITO e GONZÁLEZ-BENITO, 2006);

- Cadeia de fornecimento sustentáveis (LINTON et al., 2007; BAI e SARKIS, 2010).

Por conseguinte, Sarkis et al. (2011, p. 3) define gestão da cadeia de suprimento verde como "[...] a integração de preocupações ambientais nas práticas inter-organizacionais da SCM, incluindo a logística reversa".

Nesse contexto, pode-se inferir que a GSCM deve compreender meios e processos que garantam a redução do uso de matéria prima e outros insumos de produção, seguido pela reutilização e reciclagem. Além disso, a responsabilidade pela logística reversa está amplamente contemplada na Política Nacional de Resíduos Sólidos, estabelecida através da Lei ${ }^{\circ}{ }^{\circ}$ 12.305/2010 (BRASIL, 2012).

Consta no referido instrumento legal, precisamente no Capítulo III, Seção II:

Art. 32:

As embalagens devem ser fabricadas com materiais que propiciem a reutilização ou a reciclagem. $\S 1^{\circ}$ Cabe aos respectivos responsáveis assegurar que as embalagens sejam: I - restritas em volume e peso às dimensões requeridas à proteção do conteúdo e à comercialização do produto; II - projetadas de forma a serem reutilizadas de maneira tecnicamente viá- vel e compatível com as exigências aplicáveis ao produto que contêm; III - recicladas, se a reutilização não for possível.

Art. 33:

São obrigados a estruturar e implementar sistemas de logística reversa, mediante retorno dos produtos após o uso pelo consumidor, de forma independente do serviço público de limpeza urbana e de manejo dos resíduos sólidos, os fabricantes, importadores, distribuidores e comerciantes [...].

Infelizmente, o Brasil encabeça uma lista de países que colecionam "leis que não pegam", ou seja, leis que nunca vicejam. Espera-se que essa, depois de quase duas décadas tramitando no Congresso, não seja mais uma delas.

Jabbour (2015) destaca que os fornecedores desempenham dupla função, ao considerar que a maneira como cooperam no proceso de estruturação da GSCM consiste no cumprimento dos requisitos técnicos/ambientais e legais impostos pela empresa, além de participar da apresentação de soluções inovadoras em apoio ao desenvolvimento de produtos.

Especificamente, no caso das agroindústrias, a gama de fornecedores é bastante variada e complexa, compondo-se daqueles com participação quase inexpressiva até aqueles considerados mais estratégicos da cadeia.

Contudo deve-se considerar que a base do ponto de partida é formada pela pressão externa e incentivos criados por diferentes grupos. Considerando o conjunto dos stakeholders, dois grupos apresentam particular relevância. Por um lado, o grupo formado pelos clientes/consumidores, uma vez que a operacionalização da cadeia de fornecimento só se justifica se os produtos e serviços oferecidos estão sendo, de fato, aceitos pelo mercado. 
Por outro lado, as regulamentações governamentais, seja de municípios, governos estaduais, governo federal ou até mesmo da comunidade internacional, apresentam extrema relevância e implicância nas atividades empresariais (SEURING e MÜLLER, 2008).

A que se considerar, ainda, que, a adoção das práticas de GSCM por parte das organizações baseia-se em motivação indireta (XU et al., 2013; MATHIYAZHAGAN et al., 2014), ou seja, pressões vindas de diferentes direções, dificultando a agilidade no processo de resposta aos stakeholders (MATHIYAZHAGAN et al., 2015).

Não obstante a isso, os fornecedores podem ser considerados fontes inevitáveis de riscos externos que incidem diretamente na gestão da cadeia de fornecimento (RAJESH e RAVI, 2015). A Figura 1 ilustra o esquema da Gestão Sustentável da Cadeia de Suprimentos.

Figura 1 - Esquema da Gestão Sustentável da Cadeia de Suprimentos.

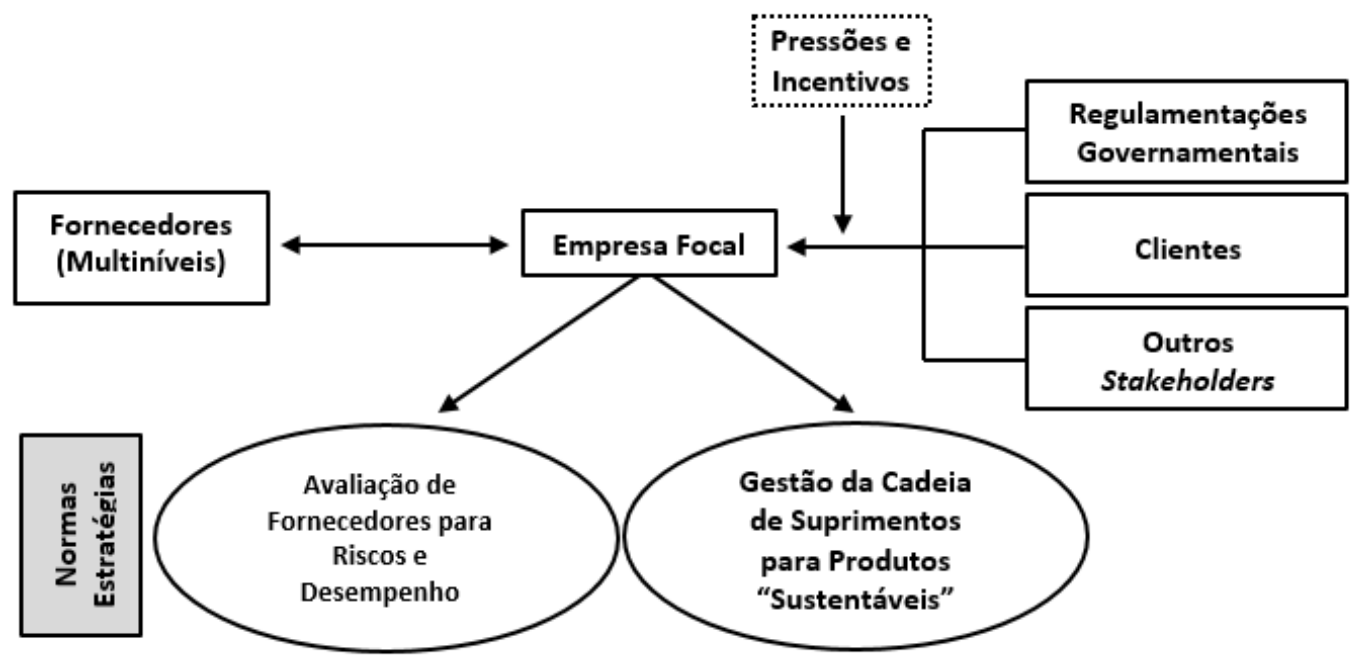

Fonte: Adaptado de SEURING e MÜLLER (2008).

Segundo Seuring e Müller (2008), as pressões e os incentivos para a adoção de práticas de sustentabilidade afetam a cooperação com fornecedores, desde a obtenção de informações sobre aspectos sociais e ambientais em relação à produção em fornecedores posicionados em elos iniciais da cadeia (ex: produção de matérias-primas) até a busca por melhoria de desempenho dos principais fornecedores da cadeia, propositura corroborada por Carvalho (2011).

O processo de cooperação entre empresa e fornecedores, contribui para amalgamar uma relação de reciprocidade entre as partes, de modo que um contribui para o aumento da eficiência operacional do outro (SANCHA et al., 2015).

\section{MATERIAIS E MÉTODOS}

\subsection{Objeto de Estudo}

Para a finalidade desse estudo será considerada a concepção clássica de região, mais especificamente de microrregião, entendida como um agrupamento de municípios limítrofes que exigem planejamento integrado para seu desenvolvimento e integração regional, que apresente, cumulativamente, características de integração funcional de natureza físico-territorial, econômicosocial e administrativa (SÃO PAULO, 1994). 
A região tem emergido como um foco essencial para pesquisadores, gestores de sustentabilidade dos recursos naturais, além dos responsáveis pelo planejamento estratégico que visa desenvolver e implementar metas de sustentabilidade (GRAYMORE et al., 2008).

A Microrregião de Assis é uma das microrregiões do Estado de São Paulo pertencente à Mesorregião de Assis, cuja população, em 2014, foi estimada em 278.220 habitantes e está dividida em 17 municípios. Possui uma área total de 7.141,738 km² (IBGE, 2014). A Figura 1 situa a Microrregião de Assis no mapa do Estado de São Paulo.

Figura 2: Mapa da Microrregião de Assis-SP com destaque para os municípios onde se localizam as organizações

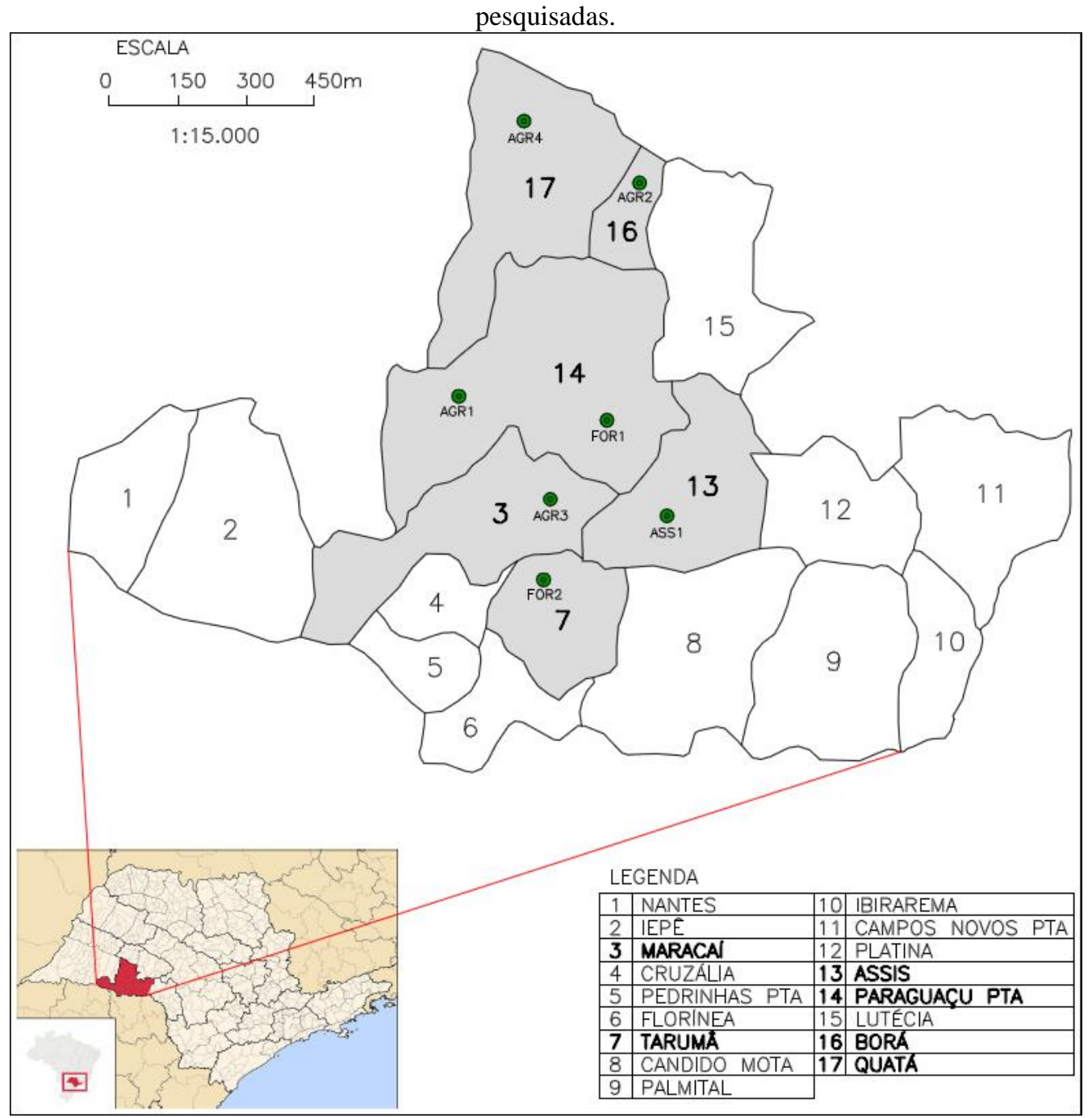

Fonte: Elaborado pelo autor.

Este espaço geográfico se caracteriza a partir de uma forte integração comercial e serviços com alto grau de sofisticação econômica e social entre os municípios que compõem a região em questão. A Microrregião possui a potencialidade de um polo modal de transportes, que se acentua com a expansão das atividades econômicas no interior de São Paulo, sobretudo o setor agrícola (OLIVEIRA et al., 2014).

A região tem experimentado um relativo desenvolvimento nos últimos anos, com predominância do agronegócio diversificado em diferentes culturas, observado o estabelecimento 
de empreendimentos agroindustriais que intensificam a integração econômica, social e cultural da Microrregião de Assis.

A Tabela 2 apresenta os dezessete municípios que formam a Microrregião de Assis, com seus respectivos números de habitantes.

Tabela 2 - Municípios da Microrregião de Assis e número de habitantes

\begin{tabular}{lc}
\hline Município & $\mathbf{N}^{\mathbf{0}}$ de habitantes \\
\hline Assis & 100.911 \\
Paraguaçu Paulista & $\mathbf{4 4 . 5 5 5}$ \\
Cândido Mota & 31.063 \\
Palmital & 22.041 \\
Maracaí & $\mathbf{1 3 . 8 7 8}$ \\
Tarumã & $\mathbf{1 4 . 0 2 7}$ \\
Quatá & $\mathbf{1 3 . 6 0 3}$ \\
Iepê & 8.002 \\
Ibirarema & 7.290 \\
Campos Novos Paulista & 4.808 \\
Platina & 3.406 \\
Pedrinhas Paulista & 3.062 \\
Florínia & 2.821 \\
Lutécia & 2.741 \\
Nantes & 2.943 \\
Cruzália & 2.234 \\
Borá & $\mathbf{8 3 5}$ \\
TOTAL & $\mathbf{2 7 8 . 2 2 0}$ \\
\hline Fonte: Elaboração própria a partir de IBGE (2014).
\end{tabular}

Observa-se a predominância de municípios com pequena população, característica típica da maioria das cidades do interior. Por outro lado, são municípios que possuem grande área territorial, o que favorece bastante a produção agropecuária e, mais especificamente, a produção canavieira.

As agroindústrias previamente selecionadas para este estudo estão localizadas nos municípios de Borá, Maracaí, Paraguaçu Paulista, Quatá e Tarumã, conforme destacado na Tabela 1.

\subsection{Caracterização dos Casos Estudados}

No intuito de garantir o anonimato das organizações pesquisadas, foram atribuídos os códigos AGR1, AGR2, AGR3 e AGR4 para as agroindústrias processadoras de cana-de-açúcar; e FOR1 e FOR2 para os fornecedores da matéria-prima (cana-de-açúcar). Todas as organizações pesquisadas estão localizadas na Microrregião de Assis, no Estado de São Paulo, abrangendo seis diferentes municípios. Para fins desse trabalho, será considerado agroindústrias, tanto as unidades processadoras quanto as unidades que atuam com exclusividade na área agrícola (fornecedores de cana-de-açúcar). O Quadro 1 apresenta uma síntese histórica de cada um dos casos estudados.

Quadro 1: Síntese histórica dos casos estudados

\begin{tabular}{|l|l|}
\hline $\begin{array}{c}\text { Casos de } \\
\text { Estudo }\end{array}$ & \multicolumn{1}{c|}{ Breve Histórico } \\
\hline \multirow{2}{*}{ AGR1 } & $\begin{array}{l}\text { De origem familiar, é uma empresa 100\% nacional, fundada em 1980, com a implantação do Proálcool. As } \\
\text { atividades iniciaram com foco na produção de etanol para o abastecimento regional, fornecendo, em 1983, } \\
\text { mais de 55 mil } \mathrm{m}^{3} \text { de etanol/ano. Em 1994 passou também a fabricar açúcar e, em 2002, acrescentou à sua } \\
\text { atuação a geração de energia elétrica, com o início da operação de sua Termoelétrica. }\end{array}$ \\
\hline
\end{tabular}




\begin{tabular}{|c|c|}
\hline AGR2 & $\begin{array}{l}\text { O Grupo que congrega a AGR2, como atualmente constituído, teve início em 1935, com a aquisição de } \\
\text { uma usina no Vale do Paraíba, região Nordeste, comandado pelo seu patriarca. Com o cultivo da cana-de- } \\
\text { açúcar se transferindo para os tabuleiros costeiros de Alagoas, o grupo instala sua segunda unidade, em } \\
\text { outro município da mesma região, tendo isto ocorrido em } 1970 \text {. Em } 1976 \text { com o advento do Proálcool o } \\
\text { grupo instala sua terceira unidade no município de Penedo. Em } 2002 \text { o grupo adquire, no estado de São } \\
\text { Paulo, uma antiga usina, rebatizada de AGR2. A produção comercial de açúcar e álcool foi iniciada em } \\
\text { 2005. A AGR2 possui capacidade para moer } 7.000 \text { toneladas de cana/dia e produz açúcares do tipo VHP e } \\
\text { Cristal, além de Álcool anidro e hidratado. }\end{array}$ \\
\hline AGR3 & $\begin{array}{l}\text { A AGR3 se destaca por ser uma empresa que compete em nível global. Possui política de investimento em } \\
\text { inovação, tecnologia e capacitação de colaboradores no intuito de aumentar sua qualificação. Está } \\
\text { atualmente entre as cinco maiores empresas em faturamento e as três maiores distribuidoras de } \\
\text { combustíveis do Brasil, sendo a principal fabricante de etanol de cana-de-açúcar do país e a maior } \\
\text { exportadora individual de açúcar de cana no mercado internacional. }\end{array}$ \\
\hline AGR4 & $\begin{array}{l}\text { A AGR4 é uma multinacional brasileira especializada em produzir açúcar, etanol, energia elétrica e } \\
\text { ingredientes para alimentação humana e nutrição animal, por meio da unidade de negócios acoplada à } \\
\text { indústria. Trata-se uma empresa com vocação industrial, que processa a cana-de-açúcar e agrega valor aos } \\
\text { produtos que dela podem ser extraídos com tecnologia voltada para a inovação. Atua em setores } \\
\text { importantes para a economia brasileira e contribui para o crescimento do país ao empregar mais de } 3.700 \\
\text { colaboradores, fomentar pesquisas em universidades nacionais e internacionais e centros de inovação, } \\
\text { comercializar energia elétrica gerada com uma fonte limpa e renovável. }\end{array}$ \\
\hline FOR1 & $\begin{array}{l}\text { A FOR1 atua no setor de produção de cana-de-açúcar, laranja in natura e suco concentrado de laranja. } \\
\text { Nasceu da divisão dos ativos de um grupo maior, fundado em } 1944 \text { e pioneiro na produção de cana no Vale } \\
\text { do Paranapanema. São cerca de } 4,5 \text { mil empregos diretos nas regiões onde atua. }\end{array}$ \\
\hline FOR & $\begin{array}{l}\text { Com suas atividades concentradas no segmento agrícola de produção de cana-de-açúcar, uma nova história } \\
\text { começou a ser construída pelo Grupo que inclui a FOR2, gerando cerca de } 2 \text { mil empregos diretos, com } \\
\text { atuação no estado de São Paulo e Mato Grosso do Sul, desde a reformulação de suas estratégias e diretrizes. } \\
\text { A FOR2 se tornou principal fornecedora de cana-de-açúcar para a empresa AGR3. A FOR2 expandiu suas } \\
\text { atividades agrícolas para disponibilizar a sua matéria-prima e criou um novo negócio em } 2011 \text { para a } \\
\text { prestação de serviços de corte, carregamento e transporte de cana-de-açúcar, a FOR2 Serviços, na busca por } \\
\text { novos clientes para a sua expansão no setor, aumentando o potencial energético das empresas envolvidas e } \\
\text { suprindo a necessidade dos parceiros. A FOR2 uniu informação, ação e resultados para que houvesse uma } \\
\text { evolução do trabalho no segmento, mantendo sua transparência nas ações e garantindo sua credibilidade. A } \\
\text { avaliação, o aprimoramento, a projeção, a inserção de novas tecnologias e a busca de soluções diárias } \\
\text { continuam sendo os focos da empresa, envolvendo o colaborador, a comunidade e o poder público. }\end{array}$ \\
\hline
\end{tabular}

Fonte: Elaborado pelo autor a partir da pesquisa documental.

Observa-se pelo resumo histórico, que todas as empresas pesquisadas possuem entre os anos 1950 e 1960, o que de certa forma, contribui para uma maior consolidação e menor suscetibilidade às mudanças e crises do mercado.

As Agroindústrias AGR1 e AGR4 são associadas à Cooperativa de Produtores de Cana-deAçúcar, Açúcar e Álcool do Estado de São Paulo, criada em 1959. Em 2008 passou a se denominar COPERSUCAR S.A. - Alimento e Energia Limpa para o Planeta; constitui-se numa sociedade anônima de capital fechado.

O paper está estruturado em quatro seções além da introdução. Na seção dois, será explanado o embasamento teórico que dará a sustentação básica à pesquisa. $\mathrm{Na}$ seção três serão apresentados os procedimentos metodológicos contendo os principais delineamentos da estrutura da pesquisa de campo (parte empírica). A seção quatro apresenta os principais resultados e discussão do trabalho. Por fim, a última seção reserva-se às conclusões finais do trabalho, incorporando as limitações da pesquisa, além de uma modesta sugestão de agenda para pesquisas futuras. 


\subsection{Procedimento Metodológico}

O estudo apresenta pressupostos qualitativos de investigação. A pesquisa qualitativa é especialmente útil quando o objetivo é entender os contornos de um fenômeno específico em seu contexto particular (FIRESTONE, 1986; WEERD-NEDERHOF, 2001; ERIKSSON e KOVALAINEN, 2008; LACH, 2014). Consoante seus objetivos mais gerais, a pesquisa é exploratória (MYERS, 2009; GIL, 2010; HERNÁNDEZ-SAMPIERI et al., 2013).

Utilizou-se o Estudo de Caso (ASMUSSEN e CRESWELL, 1995; YIN, 2010), cuja metodologia permite desenhar, a partir de várias fontes de evidência (LLEWELLYN e NORTHCOTT, 2007; YIN, 2010), uma análise simultânea da dinâmica dos fatos em uma única configuração (EISENHARDT, 1989), proporcionando uma melhor compreensão dos fenômenos organizacionais (LEE et al., 2007), o que faz do método uma alternativa credível aos estudos empreendidos no âmbito das organizações empresariais (KIRIDENA e FITZGERALD, 2006).

Nesse contexto, optou-se por empregar o estudo de casos múltiplos (STAKE, 2005), em função da possibilidade de análise entre os casos. Para Stravos e Westberg (2009) o uso de múltiplos casos acrescenta confiança aos resultados, além de ajudar na proteção de ocorrência de vieses por parte do pesquisador (VOSS et al., 2002), permitindo-lhe estabelecer comparações entre os casos estudados, descobrindo possíveis particularidades ou a existência de um padrão comum de ocorrências, o que sugere a existência de uma regularidade empírica (TSANG, 2013), além de possibilitar a criação de uma teoria mais robusta uma vez que as proposições estão mais profundamente fundamentadas na evidência empírica variada (EISENHARDT e GRAEBNER, 2007).

Dessarte, a construção da validade do estudo de caso é reforçada pelo uso de múltiplas fontes de evidência, que podem incluir vários pontos de vista dentro e entre as fontes de dados (LEONARD-BARTON, 1990; CRESWELL, 2014; SINGH, 2014).

$\mathrm{O}$ instrumento de coleta de dados foi a entrevista apoiada em roteiro semiestruturado, realizadas com os atores diretamente envolvidos com a área de logística e suprimentos das organizações em estudo, no intuito de levantar informações que auxiliassem no atendimento do objetivo da pesquisa (DELMAS e TOFFEL, 2004; CORDEIRO et al., 2009; LÓPEZ-GAMERO et al., 2010; MARTINS, 2012). Além disso, o relato de experiências de gestores contribuiu para o aumento significativo do interesse prático dos resultados (FISHER, 2007).

No processo de entrevista semiestruturada o pesquisador fica livre para fazer perguntas relacionadas que não foram previamente imaginadas e que não estavam originalmente incluídas. Essa abordagem pode resultar no surgimento de informações inesperadas e esclarecedoras, melhorando as descobertas (HAIR et al., 2005).

Complementarmente, adotou-se a análise documental (GIL, 2009), inicialmente nos websites das organizações $\mathrm{e}$, posteriormente, com mais exclusividade nos documentos comprobatórios cedidos pelas empresas. Salienta-se que, algumas das empresas permitiram cópias para análise posterior; entretanto, a maioria permitiu que a verificação e análise fossem feitas na própria empresa. Nestes casos, foi necessária uma segunda visita para esta finalidade.

Esforços foram envidados no sentido de buscar possíveis convergências e divergências no conjunto de dados coletados. Foram necessários realizar novos contatos, via e-mail, telefone e até mesmo novas visitas, a fim de obter melhores esclarecimentos sobre determinadas situações.

Como ferramenta de auxílio na análise de conteúdo utilizou-se o software ATLAS.ti versão 7 , tendo em vista o volume de informações coletadas e transcritas. Foram tomadas as devidas precauções a fim de evitar problemas decorrentes do uso de softwares no auxílio ao tratamento 
interpretativo de dados, sobretudo a alienação do pesquisador e a consequente reificação dos códigos, o que leva a análise a se tornar mecânica e distante da essência dos dados (BANDEIRADE-MELLO e CUNHA, 2004). Cabe destacar o entendimento de Lage e Godoy (2008, p. 96), ao afirmarem que:

\begin{abstract}
A despeito das facilidades obtidas com os novos recursos, o software não pode ser visto como o senhor da pesquisa [...]. Os pesquisadores são os atores do processo. A ferramenta é um recurso que pode, se bem utilizado, facilitar o gerenciamento dos arquivos, agilizar a codificação e busca de respostas, além de facilitar a comunicação. Mas quem decide o que fazer, quando fazer e por que fazer continua sendo o pesquisador.
\end{abstract}

Nesse contexto, utilizou-se da abordagem qualitativa de pesquisa e escolher o software de análise também se constitui um processo investigativo, tendo em vista não se conceber as técnicas e o uso de ferramentas como algo dissociado do pensamento mais abrangente sobre o objeto e abordagem de pesquisa (KLÜBER, 2014).

\title{
4. RESULTADOS E DISCUSSÃO
}

\subsection{O Caso AGR1}

$\mathrm{Na}$ agroindústria codificada como AGR1, foram entrevistados quatro gestores diretamente ligados às áreas ambientais e de logística. $\mathrm{O}$ Quadro 2 apresenta a quantidade de entrevistados e seus respectivos cargos corporativos.

Quadro 2 - Número de entrevistados e respectivos cargos corporativos da AGR1

\begin{tabular}{|c|c|c|l|}
\hline Casos estudados & Quantidade de Entrevistados & $\mathbf{N}^{\mathbf{0}}$ & \multicolumn{1}{|c|}{ Cargos } \\
\hline \multirow{3}{*}{ AGR1 } & \multirow{3}{*}{04} & $\mathbf{1}$ & Técnico Ambiental \\
\cline { 3 - 4 } & & $\mathbf{2}$ & Supervisor do Setor de Bem Estar \\
\cline { 2 - 4 } & & $\mathbf{3}$ & Supervisor de Plantio (Setor Agrícola) \\
\cline { 3 - 5 } & & $\mathbf{4}$ & Diretor de Pessoas \\
\hline
\end{tabular}

Fonte: Elaboração própria.

Após análise de conteúdo aplicada com o auxílio do software ATLAS.ti.7, observa-se a presença de duas ocorrências para a "Influência da Variável Ambiental na Seleção de Fornecedores".

Levando-se em consideração o porte da empresa, a quantidade de entrevistados, julga-se pouco expressivo o número de ocorrências para essa questão em particular. Nota-se, na fala de um dos entrevistados, uma tentativa de inserir a variável ambiental no contexto corporativo de seus fornecedores por imposição. O excerto "a intenção é cobrar o pessoal terceirizado e fornecedores [...] só que lá na empresa deles a gente não tá podendo exigir nada ainda; nada amarrado em contrato", deixa evidente a visão impositiva e errônea de se estabelecer na gestão da cadeia de suprimentos, questões relevantes como as que se referem às questões ambientais.

Ora, se o parceiro comercial não apresenta os critérios mínimos estabelecidos pela empresa, não deve ser contratado; não deve ser firmado contrato de parceria de trabalho. É uma atitude contraproducente no processo de gestão, a empresa firmar parceria de fornecimento, aliançar-se com o fornecedor na cadeia de suprimentos e, posteriormente, fazer intervenções no sistema de gestão do fornecedor. Não cabe à empresa focal esse papel. Trata-se do estabelecimento de relacionamento interorganizacional (PARMIGIANI e RIVERA-SANTOS, 2011) que priorize a sustentabilidade. A Figura 3 apresenta o número de ocorrências e os excertos das entrevistas detectados na análise que corroboram a análise e os argumentos apresentados. 
Figura 3 - Número de ocorrências e excertos das entrevistas da AGR1

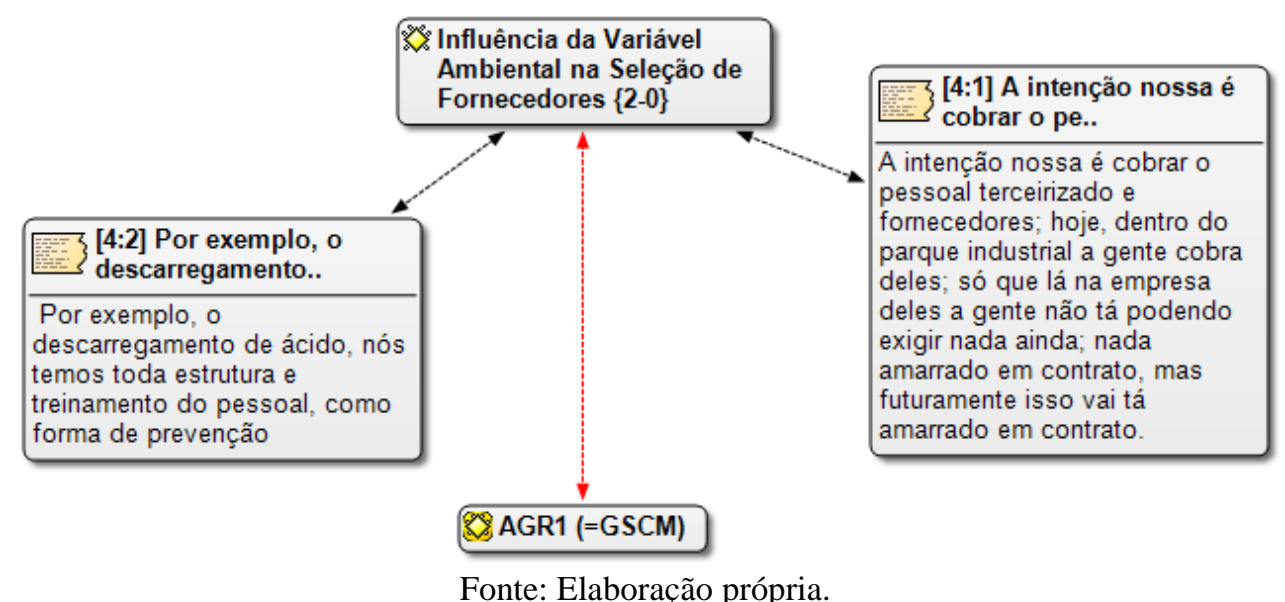

Tal atitude evidencia que a empresa não adota critérios preestabelecidos que regulamente o ordenamento de seleção e contratação de fornecedores, mormente com relação aos aspectos ambientais, o que contraria até mesmo os pressupostos básicos da gestão ambiental empresarial e sua relação com sua cadeia de suprimentos (SHARFMAN et al., 1997; HADEN et al., 2009).

Além disso, cabe à empresa, no papel de stakeholders, exercer influência para que os players considerados estratégicos para seu negócio, especialmente na consolidação da sua vantagem competitiva, incorporem proativamente os aspectos ambientais em seu negócio. Nesse sentido, apregoa Carvalho (2011), a influência dos stakeholders pode ser fator determinante na adoção de práticas sustentáveis pela empresa com repercussão positiva na construção de uma cadeia de suprimentos com foco na sustentabilidade (MEIXELL e LUOMA, 2015).

\subsection{O Caso AGR2}

Na AGR2 foram realizadas três entrevistas com gestores ligados às áreas de interesse da pesquisa. O Quadro 3 apresenta o número de entrevistados e seus respectivos cargos.

Quadro 3 - Número de entrevistados e respectivos cargos corporativos da AGR2

\begin{tabular}{|c|c|c|l|}
\hline Casos estudados & Quantidade de Entrevistados & $\mathbf{N}^{\mathbf{0}}$ & \multicolumn{1}{|c|}{ Cargos } \\
\hline \multirow{3}{*}{ AGR2 } & \multirow{3}{*}{03} & $\mathbf{1}$ & Coordenadora Socioambiental \\
\cline { 2 - 4 } & & $\mathbf{2}$ & Supervisor Agrícola \\
\cline { 2 - 4 } & & $\mathbf{3}$ & Técnico em Química \\
\hline
\end{tabular}

Fonte: Elaboração própria.

A agroindústria pesquisada apresentou somente uma ocorrência que faz menção à influência da variável ambiental na seleção e contratação de seus fornecedores. No relato de um dos entrevistados, há evidências claras sobre a logística reversa: "[...] hoje o que a gente busca muito com nossos fornecedores é a logística reversa". Todavia, a fala não comprova a existência de critérios ambientais na escolha de seus fornecedores, o que pode ser constatado, também, pela ausência de documentos, contrariando a proposta inserida na revisão de literatura (ZHU e SARKIS, 2004; SARKIS et al., 2011; BRASIL, 2012).

Nitidamente, o que se percebe é que a preocupação em descartar o material inutilizado ou, ainda, em atender à legislação, suplanta a preocupação com os aspectos ambientais, propriamente ditos (JABBOUR et al., 2015). Sem embargo, o contexto atual, de forte intensificação das normas reguladoras e diretrizes ambientais na ambiência externa, provoca aumento da pressão sobre as 
organizações para que tomem medidas no mínimo preventivas quanto ao aspecto ambiental (KOH et al., 2012).

A Figura 4, exportada do software ATLAS.ti.7, dá uma visão geral do excerto da entrevista transcrita em que ocorre essa assertiva.

Figura 4 - Número de ocorrências e excertos das entrevistas da AGR2

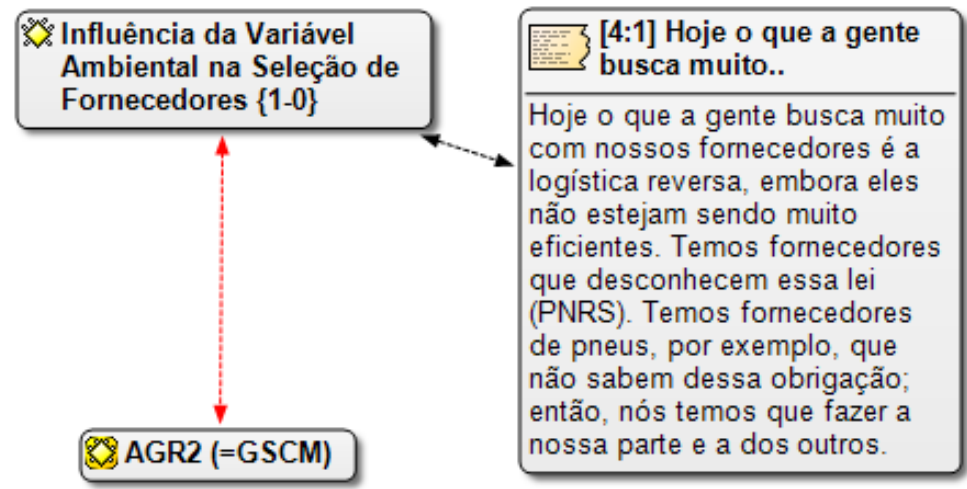

Fonte: Elaboração própria.

Chama a atenção a segunda parte do excerto do depoente quando afirma que "Temos fornecedores de pneus, [...] que não sabem dessa obrigação; então, nós temos que fazer a nossa parte e a dos outros". Depreende-se, portanto, que, alguns integrantes da cadeia de suprimentos dessa agroindústria desconhece a Política Nacional de Resíduos Sólidos. Até aqui nada de novo, haja vista o fato de que esse desconhecimento pode ter maior amplitude do que se imagina, o que é lamentável.

Reconhece-se a complexidade do ambiente externo, o que torna moroso o processo de tomada de decisão por parte dos gestores (MATHIYAZHAGAN et al., 2015). Contudo, isso não justifica a ausência de envide de esforços na implementação de uma gestão mais eficiente, considerando a possibilidade de vantagens competitivas (RONDA-PUPO e GUERRAS-MARTIN, 2012).

Contudo, torna-se inexplicável, pelo menos à primeira vista, o fato de a empresa ter que "fazer a nossa parte e a dos outros". Como isso é possível? Se existe alguma possibilidade que porventura não foi captada nesse estudo, então, qual o custo disso? Com certeza, extremamente elevado. Fica claro que, para essa empresa, a influência da variável ambiental na escolha, seleção e possível contratação de seus fornecedores é significativamente inexpressiva.

\subsection{O Caso AGR3}

Na AGR3 foram entrevistados três atores envolvidos nas áreas foco da pesquisa, sendo um analista, um gerente corporativo e um coordenador administrativo. O Quadro 4 sistematiza essas informações para melhor visualização.

Quadro 4 - Número de entrevistados e respectivos cargos corporativos da AGR3

\begin{tabular}{|c|c|c|l|}
\hline Casos estudados & Quantidade de Entrevistados & $\mathbf{N}^{\mathbf{0}}$ & \multicolumn{1}{|c|}{ Cargos } \\
\hline \multirow{3}{*}{ AGR3 } & \multirow{3}{*}{03} & $\mathbf{1}$ & Analista de Meio Ambiente \\
\cline { 2 - 4 } & & $\mathbf{2}$ & Gerente Corporativo de Meio Ambiente \\
\cline { 2 - 4 } & & $\mathbf{3}$ & Coordenador Administrativo \\
\hline
\end{tabular}

Fonte: Elaboração própria. 
A agroindústria apresentou três ocorrências que refletem uma influência mais imperativa dos aspectos ambientais na relação com seus players na cadeia de suprimentos. Além dos depoimentos obtidos e transcritos, a análise documental corroborou a assertiva do entrevistado ao apontar que "Quanto aos fornecedores, nós temos procedimentos adotados com relação aos resíduos, documentação, entre outros. Toda verificação do fornecedor é exigida [...]”.

Talvez pelo fato de a AGR3 pertencer a um grupo multinacional, haja maior eficiência operacional na gestão da cadeia de suprimentos, notadamente no que concerne aos aspectos ambientais. Essa agroindústria é certificada pelo Better Sugarcane Initiative - Bonsucro, através de uma organização global com sede no Reino Unido. Pelo exposto na Figura 5, especificamente no ponto 4:3, verifica-se que a organização está comprometida em expandir essa certificação aos seus fornecedores, sendo que, para alcançar esse objetivo, tem procedido "uma qualificação dos fornecedores de cana [...]".

Evidentemente, ao empreender esforços para alcançar o objetivo proposto, a agroindústria se insere juntamente com seus fornecedores numa atmosfera de cooperação (SEURING e MÜLLER, 2008) na busca por melhoria de desempenho (CARVALHO, 2011). A Figura 5 ilustra as três ocorrências com os excertos que as caracterizam, aferidas a partir da análise de conteúdo.

Figura 5 - Número de ocorrências e excertos das entrevistas da AGR3

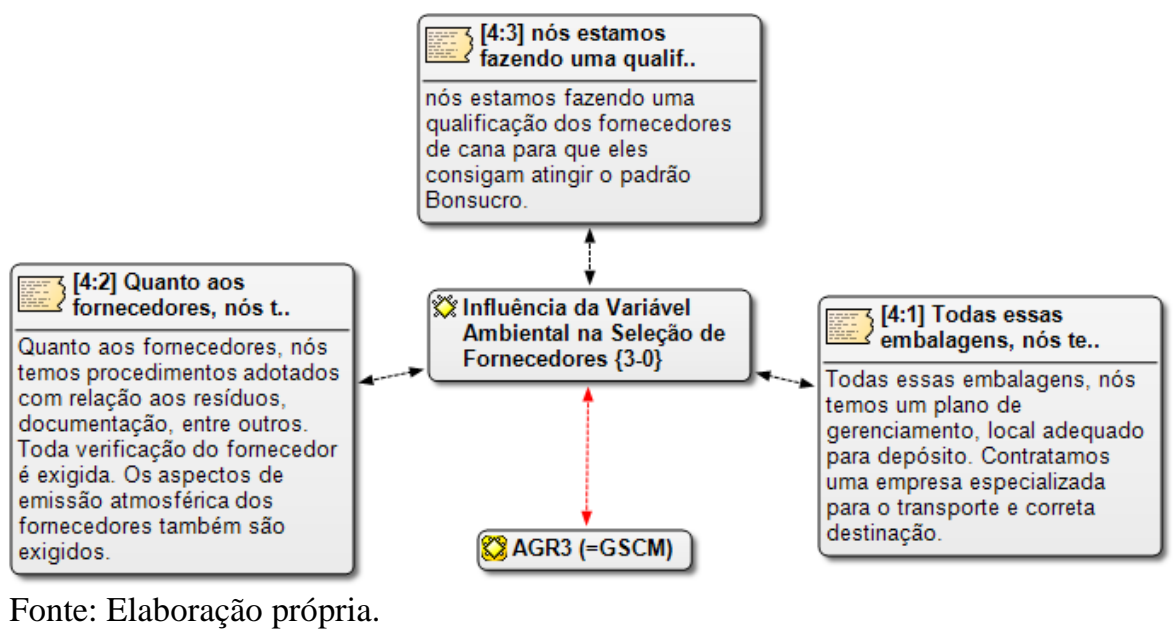

De modo geral, a AGR3 se apresenta como uma das empresas com maior eficiência no gerenciamento de sua cadeia de suprimentos, analisada a partir da inclusão da variável ambiental na seleção dos seus fornecedores.

Por outro lado, conta positivamente a favor da empresa o fato de promover gestão no sentido de preparar/qualificar seus fornecedores a alcançarem uma certificação internacional, por ela já obtida.

\subsection{O Caso AGR4}

Diferentemente das demais empresas até aqui analisadas, a AGR4 apresenta uma singularidade que a coloca num patamar mais elevado no que tange à gestão sustentável da sua cadeia de suprimentos, vista pela ótica da influência da variável ambiental na seleção de fornecedores. Na AGR4 foi entrevistado somente o analista de preservação ambiental, uma função corporativa do grupo. O Quadro 5 demonstra o cargo do entrevistado. 
Quadro 5 - Número de entrevistados e respectivos cargos corporativos da AGR4

\begin{tabular}{|c|c|c|c|}
\hline Casos estudados & Quantidade de Entrevistados & $\mathbf{N}^{\mathbf{0}}$ & Cargos \\
\hline AGR4 & 01 & $\mathbf{1}$ & Analista de Preservação Ambiental \\
\hline
\end{tabular}

Fonte: Elaboração própria.

A particularidade refere-se ao fato de que, apesar de ter sido entrevistado somente um ator envolvido com a temática, a pesquisa documental proporcionou maior robustez ao processo de análise de análise dos dados. Assim, do total de onze ocorrências aferidas no exame detalhado do conteúdo, sete foram obtidas diretamente do código de conduta, documento oficial da empresa. A Figura 6 apresenta a totalidade das ocorrências e os respectivos excertos da entrevista e da análise documental.

Figura 6 - Número de ocorrências e excertos das entrevistas da AGR4

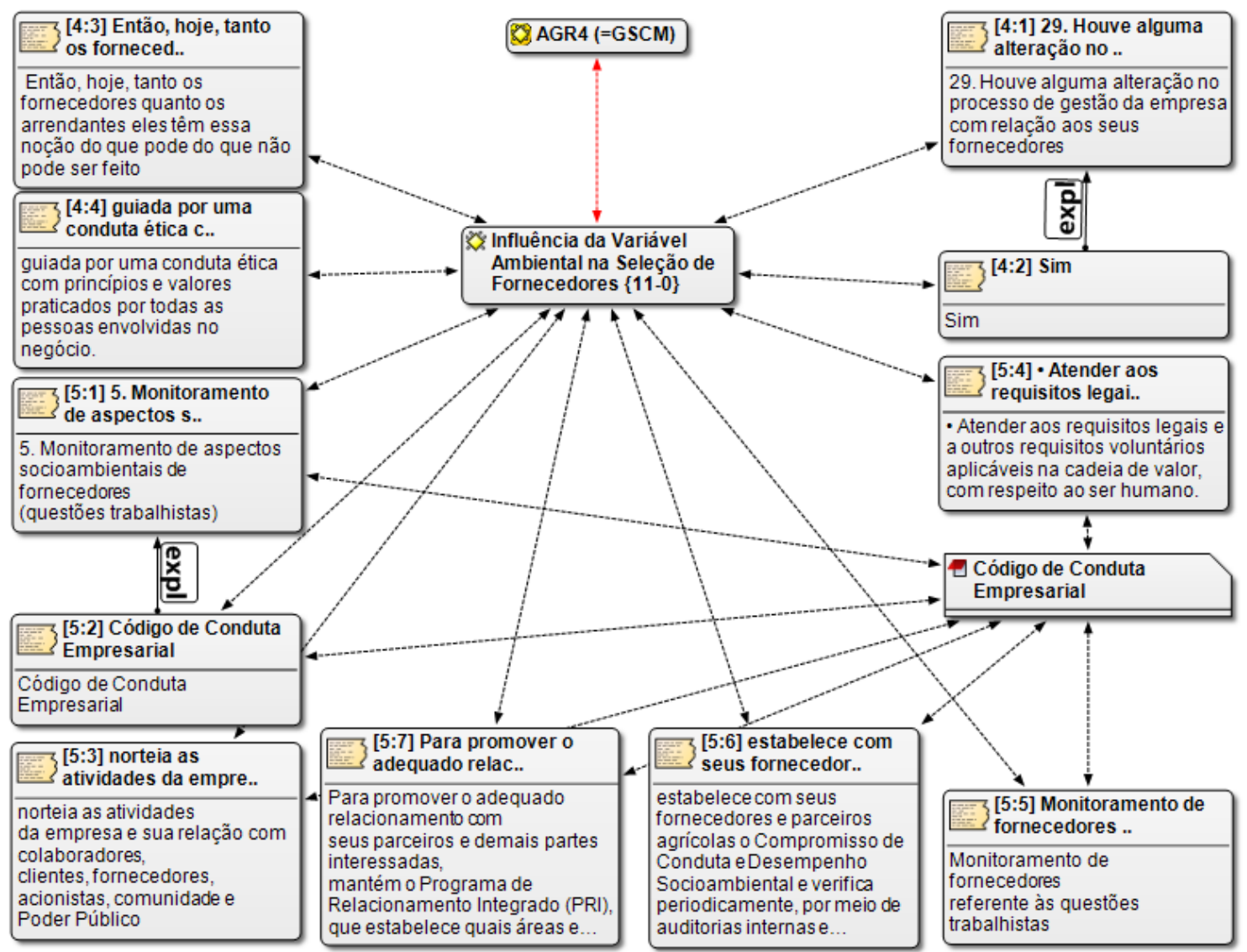

Fonte: Elaboração própria.

Observa-se que o excerto codificado 4:2 refere-se à resposta do questionamento do excerto 4:1 que, por sua vez, reporta-se à questão $n^{\circ} 29$ do roteiro semiestruturado. Na ilustração, portanto, fica evidenciado as referências à entrevista e à análise do código de conduta da empresa em questão.

Uma característica que se destaca na AGR4 remete à proposta de cooperação, com ganhos mútuos, postulada por Sancha et al. (2015). É notório que a formalização de um documento que contenha os princípios norteadores das práticas empresariais, o Código de Conduta, agrega valor às relações da empresa com toda sua cadeia, tanto a jusante quanto à montante. 


\subsection{O Caso FOR1}

Embora a análise de conteúdo realizada pelo software ATLAS.ti.7 tenha apontado uma variável (Figura 7), com menção direta aos seus fornecedores, inclusive com destaque para um número significativo deles "Temos muitos fornecedores, de peças, combustíveis, máquinas $e$ equipamentos [...]", a informação sobre a influência da variável ambiental na seleção de fornecedores é inexistente, ou seja, totalmente nula.

Aliás, como demonstra o próprio excerto da entrevista “[...] nós não tivemos que fazer um trabalho com eles", notabiliza que a empresa não os considera em sua gestão da cadeia de suprimentos.

Na FOR1 foram entrevistados três profissionais, conforme demonstrado no Quadro 6.

Quadro 6 - Número de entrevistados e respectivos cargos corporativos da FOR1

\begin{tabular}{|c|c|c|l|}
\hline Casos estudados & Quantidade de Entrevistados & $\mathbf{N}^{\mathbf{0}}$ & \multicolumn{1}{c|}{ Cargos } \\
\hline \multirow{3}{*}{ FOR1 } & \multirow{3}{*}{03} & $\mathbf{1}$ & Gerente Agrícola \\
\cline { 2 - 4 } & & $\mathbf{2}$ & Técnico de Segurança do Trabalho e Meio Ambiente \\
\cline { 2 - 4 } & & $\mathbf{3}$ & Analista Ambiental \\
\hline
\end{tabular}

Fonte: Elaboração própria.

O gerente agrícola é o profissional que está diretamente ligado ao setor de logística, uma vez que, além da gerência agrícola, acumula o cargo de supervisão geral. A FOR1 não apresenta evidências mínimas de gestão com os demais atores institucionais da sua cadeia de suprimento e abastecimento, sobretudo no aspecto ambiental.

Nesse sentido, deve a empresa focal exercer influência na criação, implementação e monitoramento da gestão de seus stakeholders, com destaque para os fornecedores, conforme apregoa Gavira (2015). Além disso, o aumento na eficiência da gestão sustentável da cadeia de suprimentos é diretamente proporcional à minimização dos riscos advindos de fontes externas como é o caso dos fornecedores (RAJESH e RAVI, 2015). A Figura 6 extraída da análise de conteúdo apresenta a ocorrência "negativa" da influência da variável ambiental na seleção de fornecedores.

Figura 6 - Número de ocorrências e excertos das entrevistas da FOR1

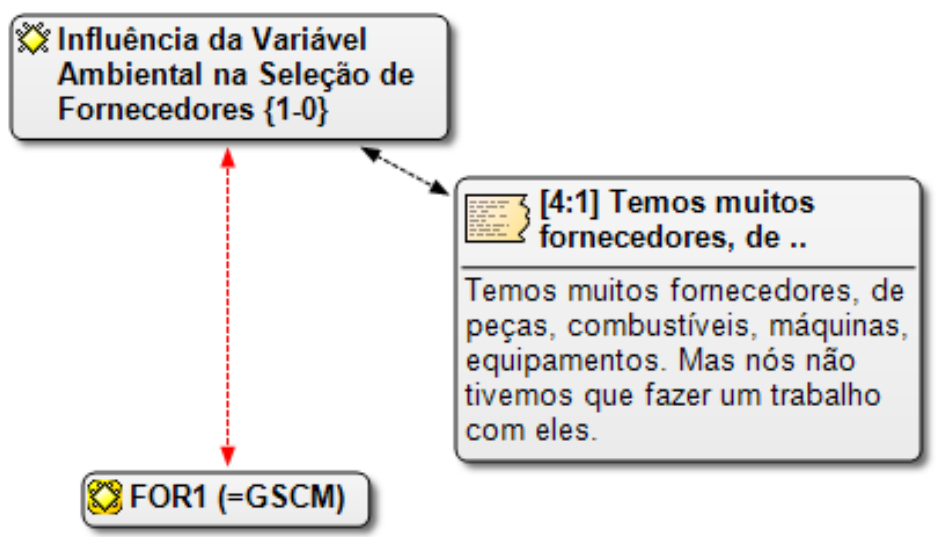

Fonte: Elaboração própria.

Não seria demais afirmar que a FOR1 corre riscos ao descuidar da gestão da sua cadeia de abastecimentos, mormente quanto aos seus fornecedores e, mais especificamente, ao negligenciar os aspectos ambientais em suas relações comerciais. 


\subsection{O Caso FOR2}

$\mathrm{Na}$ organização FOR2 foram realizadas duas entrevistas, sendo que os dois depoentes estão alocados no nível de supervisão: supervisor de planejamento agronômico e supervisor de controle e custos agrícolas. O Quadro 7 sistematiza essas informações.

Quadro 7 - Número de entrevistados e respectivos cargos corporativos da FOR2

\begin{tabular}{|c|c|c|l|}
\hline Casos estudados & Quantidade de Entrevistados & $\mathbf{N}^{\mathbf{0}}$ & \multicolumn{1}{|c|}{ Cargos } \\
\hline \multirow{2}{*}{ FOR2 } & \multirow{2}{*}{02} & $\mathbf{1}$ & Supervisor de Planejamento Agronômico \\
\cline { 2 - 4 } & & $\mathbf{2}$ & Supervisor de Controle e Custos Agrícolas \\
\hline
\end{tabular}

Fonte: Elaboração própria.

Ressalta-se que os entrevistados estão diretamente ligados às áreas de logística, sendo que o supervisor de planejamento agronômico responde pela área ambiental da empresa.

Foram detectadas quatro ocorrências na análise da FOR2. Contudo, uma delas, embora faça menção direta à existência de uma gerência exclusiva de relacionamento com fornecedor e suprimentos, não se identificou menção alguma à questão ambiental. Na ocorrência codificada 4:2, observa-se que a empresa deixou de realizar o controle das emissões de seus fornecedores de matéria-prima. Por outro lado, quanto aos ônibus contratados para o transporte de seus funcionários, a FOR2 exige que seja apresentado comprovante de controle das emissões de poluentes.

Via de regra, nota-se uma preocupação mais acentuada da FOR2 em atender à legislação, minimizando os riscos de penalidades, o que caracteriza uma reação predominantemente reativa da empresa (AZZONE e BERTELÉ, 1994; VASTAG et al., 1996; JABBOUR, 2010). A Figura 7 ilustra as ocorrências extraídas da análise de conteúdo.

Figura 7 - Número de ocorrências e excertos das entrevistas da FOR2

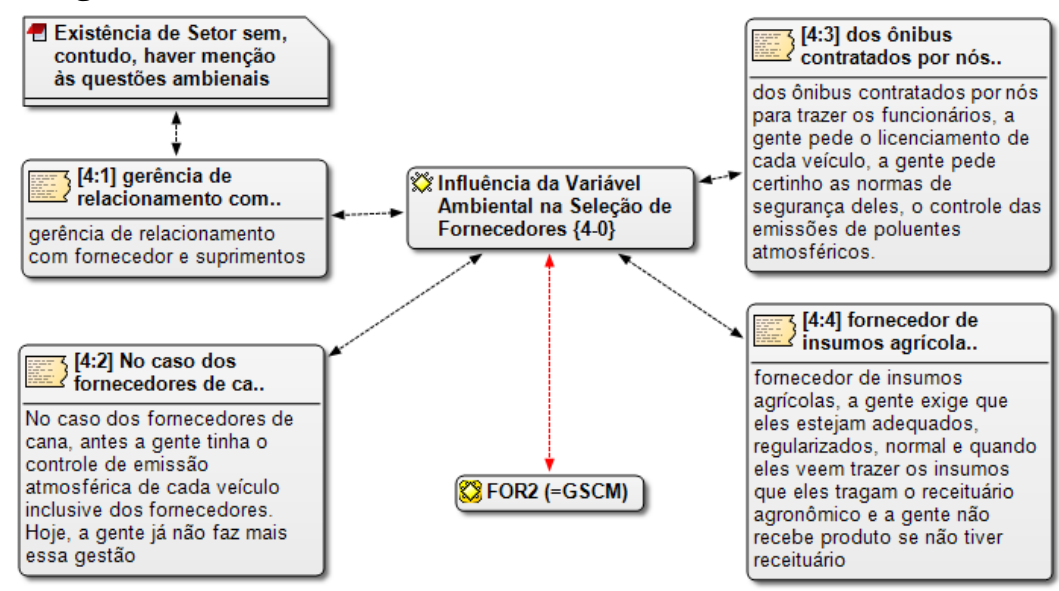

Fonte: Elaboração própria.

Fica evidente, portanto, que a variável ambiental exerce pouca ou nenhuma influência na sua relação com seus stakeholders, mormente como critério de seleção e contratação de seus parceiros que comporão a sua cadeia de suprimentos. 


\section{CONCLUSÃO}

Esse paper teve como objetivo precípuo analisar a influência da variável ambiental introduzida nas decisões e seleção dos fornecedores das agroindústrias de cana-de-açúcar localizadas na Microrregião de Assis-SP, região predominantemente canavieira.

Os resultados mostraram influência forte da variável ambiental na seleção de fornecedores somente nas agroindústrias AGR3 e AGR4. A influência na AGR1 é mediana e fraca nas agroindústrias AGR2, FOR1 e FOR2.

Levando-se em consideração que a sustentabilidade é um caminho sem volta, portanto, não se trata de um modismo corporativo passageiro, uma vez que as empresas são um dos atores nesse palco institucional, cabe às empresas envidar esforços no aprimoramento da gestão da sua cadeia de suprimentos, sobretudo abarcando os aspectos ambientais.

Os riscos são extremamente elevados e envolvem os aspectos econômicos, sociais e ambientais, tanto da empresa focal, quanto da sua cadeia de suprimentos. Dessa forma, o custo da omissão pode ser incalculável diante de uma ocorrência que envolva a reputação da corporação.

Embora a região de realização da pesquisa seja majoritariamente canavieira e, mesmo tendo abarcado as principais - capacidade de produção (toneladas de cana processada) -, agroindústrias, o estudo limitou-se somente ao recorte geográfico proposto. Outra limitação refere-se ao fato de ter ficado restrito somente ao aspecto ambiental da sustentabilidade, deixando num segundo plano os aspectos sociais e econômicos.

Sugere-se que outros estudos possam ampliar o campo de investigação, incluindo outras agroindústrias de outras regiões com destaque na produção sucroenergética, além de contemplar os aspectos econômicos e sociais na relação de negócios dos players.

Espera-se que, minimamente, esta pesquisa possa contribuir para futuros estudos no campo da Green Supply Chain Management - GSCM, sobretudo ao ter como sujeito de pesquisa as indústrias do setor sucroenergético, em função de suas especificidades e expectativas promissoras no campo da bioenergia.

\section{REFERENCIAS}

ASMUSSEN, K. J; CRESWELL, J. W. Campus Response to a Student Gunman. The Journal of Higher Education, v. 66, n. 5, p. 575-591, sep./oct., 1995. Disponível em 〈http://www.jstor.org/stable/2943937>. Acesso em 24 mar 2015.

AZZONE, G.; BERTELÉ, U. Exploiting green strategies for competitive advantage. Long Range Planning, v. 27, n. 6, p. $69-81,1994$.

BAI, C.; SARKIS, J. Integrating sustainability into supplier selection with grey system and rough set methodologies. International of Journal Production Economics, v. 124, p. 252-264. 2010. doi:10.1016/j.ijpe.2009.11.023.

BANDEIRA-DE-MELLO, R.; CUNHA, C. J. C. A. Administrando o risco: uma teoria substantiva da adaptação estratégica de pequenas empresas a ambientes turbulentos e com forte influência governamental. Revista de Administração Contemporânea -RAC, Edição Especial, p. 157-179, 2004.

BAUEN, A. Avaliação das questões relativas às externalidades e à sustentabilidade. In: ROSILLO-CALLE, F.; BAJAY, S. V.; ROTHMAN, H. (Orgs.). Uso da biomassa para produção de energia na indústria brasileira. Campinas-SP: Editora da UNICAMP, 2005.

BESKE, P.; SEURING, S. Putting sustainability into supply chain management. Supply Chain Management: An International Journal, v. 19, n. 3, p. 322-331, 2014. oi.org/10.1108/SCM-12-2013-0432.

BRASIL. Lei $\mathbf{n}^{\circ}$ 12.305, de 2 de Agosto de 2010. Política Nacional de Resíduos Sólidos. 2. ed. - Brasília/DF: Câmara dos Deputados, Edições Câmara, 2012. 
CARTER, C. R.; KALE, R.; GRIMM, C. M. Environmental purchasing and firm performance: an empirical investigation. Transportation Research Part E, v. 36, p. 219-228, 2000. PII: S1366-5545(99)00034-4.

CARTER, C. R.; ROGERS, D. S. A framework of sustainable supply chain management: moving toward new theory. International Journal of Physical Distribution \& Logistics Management, v. 38, n. 5, p. 360-387, 2008. DOI $10.1108 / 09600030810882816$.

CARVAlHO, A. P. Gestão Sustentável de Cadeias de Suprimento: análise da indução e implementação de práticas socioambientais por uma empresa brasileira do setor de cosméticos. 2011. 216 f. (Tese Doutorado). Fundação Getúlio Vargas - FGV, São Paulo, 2011

CHRISTIE, I.; ROLFE, H.; LEGARD, R. Cleaner production in industry: integrating business goals and environmental management. London: Policy Studies Institute, 1995.

COOPER, M. C.; LAMBERT, D. M.; PAGH, J. D. Supply Chain Management: more than a new name for logistics. The International Journal of Logistics Management, v. 8, n. 1, p. 1-14, 1997. doi.org/10.1108/09574099710805556.

CORDEIRO, J. J.; ZHU, Q.; SARKIS, J. International and domestic pressures and Chinese organizational responses to greening. The Academy of Management Proceedings - Annual Meeting Proceedings: Green Management Matters, 2009. doi: 10.5465/AMBPP.2009.44251848.

CRESWELL, J. W. Investigação qualitativa \& projeto de pesquisa - escolhendo entre cinco abordagens. 3. ed. Porto Alegre: Penso, 2014.

CRUZ, J. M.; MATSYPURA, D. Supply chain networks with corporate social responsibility through integrated environmental decision-making. International Journal of Production Research, v. 47, n. 3, p. 621-648, 2009. DOI: $10.1080 / 00207540701513901$.

DELMAS, M.; TOFFEL, M. W. Stakeholders and environmental management practices: an institutional framework. Business Strategy and the Environment, v. 13, n. 4, p. 209-222, 2004. DOI: 10.1002/bse.409.

DIMAGGIO, P. J.; POWELL, W. W. The new institutionalism in organizational analysis. Chicago: University Chicago Press, 1991.

EISENHARDT, K. M. Building theories from case study research. The Academy of Management Review, v. 14, n. 4, p. 532-550, 1989. Disponível em < http://www.jstor.org/stable/258557>. Acesso em 25 fev. 2015.

EISENHARDT, K. M.; GRAEBNER, M. E. Theory building from cases: opportunities and challenges. Academy of Management Journal, v. 50, n. 1, p. 25-32, 2007. doi: 10.5465/AMJ.2007.24160888.

EMMETT, S.; SOOD, V. Green Supply Chains - An action manifesto. United Kingdon: John Wiley \& Sons Ltd., 2010.

ERIKSSON, P.; KOVALAINEN, A. Qualitative Methods in Business Research. London: Sage, 2008.

FIRESTONE, W. A. Meaning in method: The rhetoric of quantitative and qualitative research. Research for Better Schools, Inc., Philadelphia, Pa., 1986. Disponível em < http://files.eric.ed.gov/fulltext/ED292816.pdf >. Acesso em 21 ev. 2015.

FISHER, M. Strengthening the Empirical Base of Operations Management. Manufacturing \& Service Operations Management, v. 9, n. 4, p. 368-382, 2007. doi:10.1287/msom.1070.0168.

GAVIRA, M. O. Sustentabilidade ambiental do setor sucroenergético. In: SALLES-FILHO, S. (Coord.). Futuros do bioetanol: o Brasil na liderança? Rio de Janeiro: Elsevier, 2015.

GIL, A. C. Estudo de Caso: fundamentação científica: subsídios para coleta e análise de dados - como redigir o relatório. São Paulo: Atlas, 2009.

GIL, A. C. Como elaborar projetos de pesquisa. 5. ed. São Paulo: Atlas, 2010.

GONZÁLEZ-BENITO, J.; GONZÁLES-BENITO, O. The role of stakeholder pressure and managerial values in the implementation of environmental logistics practices. International Journal of Production Research, v. 44, n. 7, p. 1353-1373, 2006. DOI: 10.1080/00207540500435199.

GONZÁLEZ-BENITO J. The Effect of Manufacturing Pro-activity on Environmental Management: an exploratory analysis. International Journal of Production Research, v. 46, n. 24, p. 7017-7038, 2008. 
GONZÁLEZ-LOUREIROM.; DABIC, M.; KIESSLING, T. Supply chain management as the key to a firm's strategy in the global marketplace - Trends and research agenda. International Journal of Physical Distribution \& Logistics Management, v. 45, n. 1/2, p. 159-181, 2015. DOI 10.1108/IJPDLM-05-2013-0124.

GRAYMORE, M. L. M.; SIPE, N. G.; RICKSON, R. E. Regional sustainability: how useful are current tools of sustainability assessment at the regional scale? Ecological Economics, v. 67, p. 362-372, 2008. doi:10.1016/j.ecolecon.2008.06.002.

GÜNTHER, E.; SCHEIBE, L. The hurdle analysis. A self-evaluation tool for municipalities to identify, analyse and overcome hurdles to green procurement. Corporate Social Responsibility and Environmental Management, v. 13, p. 61-77, 2006. DOI: 10.1002/csr.092.

HADEN, S. S. P.; OYLER, J. D.; HUMPHREYS, J. H. Historical, practical, and theoretical perspectives on green management: An exploratory analysis. Management Decision, v.47, n. 7, p.1041-55, 2009. doi.org/10.1108/00251740910978287.

HAIR, J. F. J.; BABIN, B.; MONEY, A. H.; SAMOUEL, P. Fundamentos de métodos de pesquisa em administração. Porto Alegre: Bookman, 2005.

HERNÁNDEZ SAMPIERI, R.; COLlADO, C. F.; LUCIO, M. del P. B. Metodologia de pesquisa. 5. ed. Porto Alegre: Penso, 2013.

$\begin{array}{lccccccc}\text { INSTITUTO } & \text { BRASILEIRO DE } & \text { GEOGRAFIA } & \text { E ESTATÍSTICA } & \text { (IBGE). } & \text { Estimativas populacionais para os } \\ \text { municípios } & \text { brasileiros } & \text { em } & \mathbf{0 1 . 0 7 . 2 0 1 4} & 2014 . & \text { Disponível } & \text { em } & <\end{array}$ ftp://ftp.ibge.gov.br/Estimativas_de_Populacao/Estimativas_2014/estimativa_dou_2014.pdf>. Acesso em 18 mar 2015.

JABBOUR, C. J. C. Non-linear pathways of corporate environmental management: a survey of ISO 14001-certified companies in Brazil. Journal of Clean Production, v.18, n.12, p.1222-1225, 2010. doi:10.1016/j.jclepro.2010.03.012.

JABBOUR, A. B. L. S. Understanding the genesis of green supply chain management: lessons from leading Brazilian companies. Journal of Cleaner Production, v. 87, p. 385-390, 2015. doi.org/10.1016/j.jclepro.2014.09.034.

JABBOUR, C. J. C.; JUGEND, D.; JABBOUR, A. L. B. S.; GUNASEKARAN, A.; LATAN, H. Green product development and performance of Brazilian firms: measuring the role of human and technical aspects. Journal of Cleaner Production, v. 87, p. 442-451, 2015. doi.org/10.1016/j.jclepro.2014.09.036.

KIRIDENA, S.; FITZGERALD, A. The case study approach in operations management research. ACSPRI Social Science Methodology Conference, Sydney - Australia, 2006. Research Online, p. 1-18, 2006. Disponível em: <http://ro.uow.edu.au/engpapers/650>. Acesso em 11 dez. 2014.

KLÜBER, T. E. ATLAS.ti como instrumento de análise em pesquisa qualitativa de abordagem fenomenológica. ETD Educação Temática Digital, v. 16, n. 1, p. 5-23, jan./abr., 2014. Disponível em < www.fae.unicamp.br/etd>. Acesso em 24 dez 2014.

KOH, S. C. L.; GUNASEKARAN, A.; TSENG, C. S. Cross-tier ripple and indirect effects of directives WEEE and RoHS on greening a supply chain. International Journal of Production Economics, v. 140, n. 1, p. 305-317, 2012. doi:10.1016/j.ijpe.2011.05.008.

KOVÁCS, G. Framing a demand network for sustainability. Progress in Industrial Ecology, an International Journal, v. 1, n. 4, p. 397-410, 2004. DOI: 10.1504/PIE.2004.005843.

LACH, D. Challenges of Interdisciplinary Research: Reconciling qualitative and quantitative methods for understanding human-landscape systems. Environmental Management, v. 53, n. 1, p. 88-93, 2014. DOI 10.1007/s00267-013-0115-8.

LAGE, M. C.; GODOY, A. S. O uso do computador na análise de dados qualitativos: questões emergentes. RAM REVISTA DE ADMINISTRAÇÃO MACKENZIE, v. 9, n. 4, p. 75-98, Edição Especial, 2008.

LAMBERT, D. M; COOPER, M. C; PAGH, J. D. Supply Chain Management: implementation issues and research opportunities. The International Journal of Logistics Management, v. 9, n. 2, p. 1-19, 1998.

LEE, B.; COLLIER, P. M.; CULLEM, J. Reflections on the use of case studies in the accounting, management and organizational disciplines. Qualitative Research in Organizations and Management: An International Journal, v. 2, n. 3, p. 169-178, 2007. doi.org/10.1108/17465640710835337.

LEONARD-BARTON, D. A dual methodology for case studies: synergistic use of a longitudinal single site with replicated multiple sites. Organization Science, v. 1, n. 3, p. 248-266, 1990. 
LINTON, J. D.; KLASSEN, R.; JAYARAMAN, V. Sustainable supply chains: an introduction. Journal of Operations Management, v. 25, p. 1075-1082, 2007. doi:10.1016/j.jom.2007.01.012.

LIPPMAN, S. Supply Chain Environmental Management. Environmental Quality Management, v.11, n.2, p.11-14, 2001. DOI: $10.1002 /$ tqem.1301.

LLEWELLYN, S.; NORTHCOTT, D. The "singular view" in management case studies. Qualitative Research in Organizations and Management: An International Journal, v. 2, n. 3, p. 194-207, 2007. doi.org/10.1108/17465640710835355.

LÓPEZ-GAMERO, M. D.; MOLINA-AZORÍN, J. F.; CLAVER-CORTÉS, E. The potential of environmental regulation to change managerial perception, environmental management, competitiveness and financial performance. Journal of Cleaner Production, v. 18, n. 10-11, p. 963-974, 2010. doi:10.1016/j.jclepro.2010.02.015.

MARTINS, R. A. Abordagens quantitativa e qualitativa. In: MIGUEL, P. A. C. (Org.). Metodologia de pesquisa em engenharia de produção e gestão de operações. 2. ed. Rio de Janeiro: Elsevier: ABEPRO, 2012.

MATHIYAZHAGAN, K.; GOVINDAN, K.; HAQ, N. Pressure analysis for green supply chain management implementation in Indian Industries Using Analytic Hierarchy Process. International Journal of Production Research, v. 52, n. 1, p. 188-202, 2014. DOI:10.1080/00207543.2013.831190.

MATHIYAZHAGAN, K.; DIABAT, A.; AL-REFAIE, A.; XU, L. Application of analytical hierarchy process to evaluate pressures to implement green supply chain management. Journal of Cleaner Production, 2015. doi: 10.1016/j.jclepro.2015.04.110. in press.

MEIXELL, M. J.; LUOMA, P. Stakeholder pressure in sustainable supply chain management: A systematic review. International Journal of Physical Distribution \& Logistics Management, v. 45, n. 1/2, p. 69-89, 2015. DOI 10.1108/IJPDLM-05-2013-0155.

MIN, H.; GALLE, W. P. Green purchasing strategies: trends and implications. International Journal of Purchasing and Materials Management, v. 33, n. 2, p. 10-17, 1997. DOI: 10.1111/j.1745-493X.1997.tb00026.x.

MURPHY, P. R.; POIST, R. F. Green Logistics Strategies: An Analysis of Usage Patterns. Transportation Journal, v. 40, n. 2, p. 5-16, 2000.

MYERS, M. D. Qualitative research in business \& management. Los Angeles: Sage Publications, 2009.

OLIVEIRA, E. C.; GASPAR, M. A.; FERNANDES, J. L. N.; SILVA FILHO, J. R. T. Análise de um aglomerado no setor sucroenergético: Estudo de caso na microrregião geográfica de Assis-SP. Revista Brasileira de Administração Científica, v. 5, n. 3, 2014. doi.org/10.6008\%2FSustenere2179-684X.2014.003.0008.

OLIVEIRA, E. C. Influência do Protocolo Agroambiental na gestão ambiental de indústrias do setor sucroenergético da Microrregião de Assis/SP: Um estudo de múltiplos casos. 2015. 391 f. (Tese Doutorado). Programa de Pós-Graduação em Administração da Universidade Municipal de São Caetano do Sul - PPGA-USCS. São Caetano do Sul-SP, 2015. Disponível em: < http://repositorio.uscs.edu.br/handle/123456789/613>. Acesso em 19 de maio de 2015.

OLIVEIRA, E. C.; PEREIRA. R. S.; GASPAR, M. A. Implementação de certificação ambiental Better Sugarcane Initiative - Bonsucro: estudo de caso no setor sucroenergético. Revista Ibero-Americana de Ciências Ambientais, v. 4, n. 2, Jun./Nov., 2013. DOI: 10.6008/ESS2179-6858.2013.002.0002.

PARMIGIANI, A.; RIVERA-SANTOS, M. clearing a path through the forest: a meta-review of interorganizational relationships. Journal of Management, v. 37, n. 4, p. 1108-1136, 2011. doi: 10.1177/0149206311407507.

PIGOU, A. C. The economics of welfare. $4^{\text {th }}$ ed. London: Macmillan, 1932. Disponível em: <http:// http://oll.libertyfund.org/titles/1410>. Acesso em 19 de maio de 2015.

RAJESH, R.; RAVI, V. Supplier selection in resilient supply chains: a grey relational analysis

approach. Journal of Cleaner Production, n. 86, p. 343-359, 2015. oi.org/10.1016/j.jclepro.2014.08.054.

RONDA-PUPO, G. A.; GUERRAS-MARTIN, L. A. Dynamics of the evolution of the strategy concept 1962-2008: a co-word analysis. Strategic Management Journal, v. 33, p. 162-188, 2012. DOI: 10.1002/smj.948.

SALLES-FILHO, S. (Coord.). Futuros do bioetanol: o Brasil na liderança? Rio de Janeiro: Elsevier, 2015.

SANCHA, C.; GIMENEZ, C.; SIERRA, V. Achieving a socially responsible supply chain through assessment and collaboration. Journal of Cleaner Production, 2015. doi: 10.1016/j.jclepro.2015.04.137. in press. 
SÃO PAULO (Estado). Lei Complementar n ${ }^{\circ} 760$, de $1^{\circ}$ de agosto de 1994. Estabelece Diretrizes para a Organização Regional do Estado de São Paulo. Diário Oficial do Estado, v. 104, n. 142, 1994.

SCOTT, W. R. Institutions and Organizations - Ideas, Interests, and Identities. $4^{\text {th }}$ ed. Stanford University, USA: SAGE Publications, Inc., 2014.

SEURING, S.; MÜLLER, M. From a literature review to a conceptual framework for sustainable supply chain management. Journal of Cleaner Production, v. 16, p. 1699-1710, 2008. doi:10.1016/j.jclepro.2008.04.020.

SEURING, S.; SARKIS, J.; MÜLLER, M.; RAO, P. Sustainability and supply chain management - An introduction to the special issue. Journal of Cleaner Production, v. 16, p. 1545-1551, 2008. doi:10.1016/j.jclepro.2008.02.002.

SHARFMAN, M. P.; ELLINGTON, R. T.; MEO, M. The next step in becoming "Green": Life-cycle oriented environmental management. Business Horizons, v. 40, n. 3, p. 13-22, 1997.

SHARFMAN, M.; SHARFT, T. M.; ANEX JUNIOR, R. P. The road to cooperative supply-chain environmental management: Trust and uncertainty among pro-active firms. Business Strategy and the Environment, v. 18, p. 1-13, 2009. DOI: $10.1002 / \mathrm{bse} .580$.

SILVA, M. E.; OLIVEIRA, E. M.; NASCIMENTO, L. F. M. Mapeamento de stakeholders sob a perspectiva da sustentabilidade: uma desk research com organizações gaúchas. RMS - Revista Metropolitana de Sustentabilidade, v. 5 , n. 1 , p. $60-77$, jan./abr. 2015 .

SINGH, A. S. Conducting case study research in non-profit organizations. Qualitative Market Research: Na International Journal, v. 17, n. 1, p. 77-84, 2014. DOI 10.1108/QMR-04-2013-0024.

SRIVASTAVA, S. K. Green supply-chain management: a state-of-the-art literature review. International Journal of Management Reviews, v. 9, n. 1, p. 53-80, 2007. DOI: 10.1111/j.1468-2370.2007.00202.x.

STAKE, R. E. Multiple Case Study Analysis. The Guildford Press: New York, 2005.

STRAVOS, C.; WESTBERG, K. Using triangulation and multiple case studies to advance relationship marketing theory. Qualitative Market Research: An International Journal, v. 12, 3. 3, p. 307-320, 2009.

TSANG, E. W. K. Case study methodology: causal explanation, contextualization, and theorizing. Journal of International Management, v. 19, n. 2, p. 195-202, 2013.

VASTAG, G.; KEREKES, S.; RONDINELLI, D. A. Evaluation of corporate environmental management approaches: a framework and application. International Journal of Production Economics, v. 43, p. 193-211, 1996.

VOSS, C.; TSIKRIKTSIS, N.; FROHLICH, M. Case research in operations management. International Journal of Operations \& Production Management, v. 22, n. 2, p. 195-219, 2002.

XU, L.; KUMAR, D. T.; SHANKAR, K. M.; DEVIKA, K.; CHEN, G. Analyzing criteria and sub-criteria for the corporate social responsibility-based supplier selection process using AHP. The International Journal of Advanced Manufacturing Technology, v. 68, n. 1-4, p. 907-916, 2013. 10.1007/s00170-013-4952-7.

WEERD-NEDERHOF, P. C. Qualitative case study research. The case of a PhD research project on organizing and managing new product development systems. Management Decision, v. 39, n. 7, p. 513-538, 2001.

YIN, R. K. Estudo de caso: planejamento e métodos. 4. ed. Porto Alegre: Bookman, 2010.

YOUNG, A.; KIELKIEWICZ-YOUNG, A. Sustainable Supply Network Management. Corporate Environmental Strategy, v. 8, n. 3, p. 260-268, 2001. doi:10.1016/S1066-7938(01)00122-1.

ZHU, Q.; SARKIS, J. Relationships between operational practices and performance among early adopters of green supply chain management practices in Chinese manufacturing enterprises. Journal of Operations Management, v. 22 , p. 265-289, 2004. doi:10.1016/j.jom.2004.01.005.

ZHU, Q.; SARKIS, J.; GENG, Y. Green supply chain management in China: pressures, practices and performance. International Journal of Operations \& Production Management, v. 25, n. 5, p. 449-468, 2005. DOI $10.1108 / 01443570510593148$.

ZSIDISIN, G. A.; SIFERD, S. P. Environmental purchasing - a framework for theory development. European Journal of Purchasing \& Supply Management, v. 7, p. 61-73, 2001. PII: S 0969 - 7012 (0 0) 00007 - 1. 